\title{
The use of different models of physical exercises performed at home during the COVID-19 pandemic: positive and negative points
}

Henrique Miguel ${ }^{1}$

Marcus Vinícius de Almeida Campos²

At the end of 2019, an outbreak of viral pneumonia caused by an unidentified microbial agent caused numerous deaths in the city of Wuhan, China. Subsequently, studies showed that the pathogen that caused the outbreak in question was a new coronavirus, which initially appeared among a group of traders who worked in the seafood market and some live animals. The cases of infection with this new virus was quickly confirmed and human transmissions appeared as the main contagion factor in the beginning of 2020. In their analysis, coronaviruses are shown as a vast family of viruses capable of causing diseases in animals and humans, with the latter ranging from symptoms of a common cold to more severe diseases such as severe acute respiratory syndrome (SARS) and Middle East Respiratory Syndrome (MERS). Thus, the disease generated by the new corona virus, received the name of COVID-19 [1,2].

There is an increasing concern on the part of the World Health Organization (WHO) and the governments of the countries, because the contamination by the virus spreads with certain ease. The main means of contamination are through physical contact between an infected person and another, mainly from the droplets of saliva of the infected individual. If these particles fall on an object, the virus can remain alive in that environment for up to 9 hours, and be active for future contamination. In other words, one should avoid touching the objects and then transferring them to the mouth, nose or eyes. In this way, constant hand hygiene, as well as a distance of at least one meter from another person, becomes more than important [2].

COVID-19 has a high degree of mortality among individuals over 60 years of age, cancer patients, people who have autoimmune diseases, people with HIV, transplantation, diabetes and hypertension. Thus, a large risk group was formed in the face of the disease, and one of the means of minimizing contagion was the need for health organizations to request social isolation in the form of quarantine. In this way, thousands of people were instructed to stay at their homes, using external services as little as possible or in case of proven need [3].

As a large part of the activities were migrated into the houses, the establishments, in turn, were forced to close, with the exception of those that address basic basic needs. The centers focused on physical exercise, for facilitating the agglomerations of people, especially at certain times, also needed to pause their activities, making practitioners have only two alternatives: to seek public places to practice or structure strategies to perform at home. On March 21, 2020, the WHO European Committee formalized a letter within the institution's daily report, requesting that any physical activity should

\footnotetext{
${ }^{1}$ Physical Education Department, University Center of Espírito Santo do Pinhal - UNIPINHAL. Av. Hélio Vergueiro Leite, s/n., Jardim Universitário I, Espírito Santo do Pinhal, SP, Brasil. Correspondence to: H MIGUEL. Email: <prhmiguel@gmail.com>.

${ }^{2}$ Physical Education Department, Faculdade Euclides da Cunha College - FEUC. São José do Rio Pardo, SP, Brasil.

$\otimes \otimes \otimes \otimes$

Como citar este artigo / How to cite this article

Miguel H, Campos MVA. The use of different models of physical exercises performed at home during the COVID-19 pandemic: positive and negative points. InterAm J Med Health 2020;3:e202003005
} 
only be carried out in quarantine. This request came after the alarming rise of COVID-19 cases in Italy and Spain [4]

In this way, exercise models are sought that can be feasible for individuals to remain active, and enjoy effective physical and mental health in a time of great social isolation. However, not all strategies that are being used, especially by professionals in the field of physical education, are suitable for all people. Below, we seek to point out some strategies that have been used more, as well as their positive and negative points.

HIIT Body Work is an intense interval training that seeks to work in a short time the metabolic and neuromuscular abilities of the practitioner. Most of the time, short intervals of high intensity exercise $(20,30$ seconds) are used, interspersed with brief rest intervals. As there is no need for devices and there is the possibility of making it in a short interval, it has become a model with great use so far. In addition, HIIT Body Work can help increase the maximum oxygen capacity and be an ally in saving energy spent during walking [5]. However, this method, in most cases, requires sudden movements of jumps and changes in the center of gravity with speed, which can, in general, compromise the soft tissues (ligaments and tendons), mainly of individuals with low degree of Physical aptitude.

Another training model that can be used is the Manual Resistance Training, where the resistance used by a training partner is used, in order to generate an external overload for carrying out concentric and eccentric actions. To perform the exercises within this model of physical work, there is also no need for devices. In addition, it is noted the easy applicability for people with different levels of physical fitness, the adequate control of movements and the quick adjustment in the load $x$ speed ratio (performed by the companion). Unfortunately, this method has its risks at the moment, because it is necessary to always do it with another person, and, according to WHO considerations, we must seek the safe distance of more than one meter from other people to reduce the possibility of contagion. In addition, the performer needs to have a brief knowledge of weight training equipment, the companion needs to be significantly stronger than the performer, and not to suffer damage due to fatigue matters for the latter [6].

A third possible model of physical work being used during quarantine is self-resisting exercise. These are carried out through an external resistance caused by the performer. That is, if the desired movement is an elbow flexion action with the right arm, the left arm will be responsible for performing the inverse resistance to this movement. Despite its simplicity, there are data in the literature that demonstrate effective muscle activation during self-resisting movements [7]. However, the effectiveness of the resistance imposed on this model does not remain constant during the protocol, due to the fatigue generated. Also, individuals who have little knowledge about strength training, will find it difficult to get the job done.

The last model is the Training with elastic resistance, performed only through an elastic band that is responsible for generating the resistance on the movement performed. Of all the strategies mentioned above, this one seems to be the most effective and efficient within a training carried out at home. There is a huge range of exercises and the intensity and volume control can be done very effectively. In addition to the low cost of the implement used (elastic band), the benefits of this model can be seen: easy applicability for several groups, need for small physical spaces, easy adaptation for the individuality and specificity of different groups and use in one or several muscle groups [8]. Currently, this training model is already used, extending to activities in small physical spaces, work exercises and certain groups of individuals who are unable to attend gyms, however, must perform resistance exercise [9].

\section{CONSIDERATIONS}

In this way, we seek to address quickly and concisely, the positive and negative points of the main models of physical training performed during this quarantine period. It is important to note that before carrying out any physical activity, the relationship between the cost $\mathrm{x}$ benefit of it needs to be a highlight. In addition, we must avoid osteoarticular damage, as well as maximizing the effectiveness of the chosen model will be essential for more effective training that generates adequate benefits for the performer.

\section{REFERENCES}

1. Lu R, Zhao X, Li H, Niu P. Genomic characterization and epidemiology of 2019 novel coronavirus: implications for virus origins and receptor binding. Lancet. 2020;395(4):56574. https://doi.org/10.1016/\$0140-6736(20) 30251-8 
2. World Health Organization. Coronavirus disease (COVID-19) Pandemic. 2020. (Accessed in 2020 March 26). Available at: <https: // www .who.int / emergencies / diseases / novel-coronavirus-2019>.

3. Fang L, Karakiulakis G, Roth M. Are patients with hypertension and diabetes mellitus at increased risk for COVID-19 infection? Lancet Respir Med. 2020;2600(20). [Online ahead of print]. https://doi.org/10.1016/\$22132600(20)30116-8

4. World Health Organization. Coronavirus disease 2019 (COVID-19) Situation Report - 62. (2020). (Accessed in 2020 March 26). Available at: <https://www. who.int/docs/default-source/coronaviruse/situationreports/20200322>.

5. Schaun GZ, Pinto SS, Silva MR, Dolinski DB, Alberton CL. Whole-Body High-intensity interval training induce similar cardiorespiratory adaptations compared with traditional high-intensity interval training and moderate-intensity continuous training in healthy men. J Strength Cond Res. 2018;32(10):2730-2742. https://doi.org/10.1519/ JSC. 0000000000002594

6. Teixeira CVLS. Manual resistance training: weight training without equipment. São Paulo: Phorte; 2011.

7. Serrau V, Driss $T$, Vandewalle $H$, Behm DG, LesneChabran E, Le Pellec-Muller A. Muscle activation of the elbow flexor and extensor muscles during selfresistance exercises: comparison of unilateral maximal cocontraction and bilateral self-resistance. J Strength Cond Res. 2012;26(9):2468-77. https://doi.org/10.1519/ JSC.0b013e3182 3bc0a2

8. Jensen J, Holmich P, Bandholm T, Zebis M, Andersen L, Thorborg K. Eccentric strengthening effect of hip-adductor training with elastic bands in soccer players: a randomized controlled trial. Brit Jour Spor Med. 2012;31(4):331-42. https://doi.org/10.1136/bjsports-2012-091095

9. Bellar DM, Muller MD, Barkley JE, Kim C-H, Ida K, Ryan EJ, et al. The effects of combined elastic- and freeweight tension vs. free-weight tension on one-repetition maximum strength in the bench press. J Str Cond Res. 2011;25(2):459-63. 